\title{
CIDI 2017

\section{Reflexões sobre métodos aplicados em design de sinalização: o planejamento para coleta de dados em ambiente público}

Reflections on methods applied in signaling design: the planning for data collection in public environment

\author{
Giulia M. C. Cornelli, Elizabeth Romani
}

sinalização, metodologia, campus, informação

Este artigo aborda o processo metodológico de um projeto de sinalização desenvolvido para o campus central da Universidade Federal do Rio Grande do Norte. Esta pesquisa tem como objetivo descrever a fase de planejamento, gerando reflexões acerca das tomadas de decisões e escolha de métodos que se adequem às especificidades inerentes ao espaço público, em que a coleta de dados é realizada por meio de entrevistas e registros in loco.

signaling, metodology, campus, information

This article approaches the methodological process of a signaling project developed for the Federal University of Rio Grande do Norte main campus. The study consists of the planning phase description, making reflections about the decision making and application of methods that fit the specifics inherent to the public space, in which the data is performed through interviews and in loco records.

\section{Introdução}

Ainda que o desenvolvimento de um sistema de sinalização seja bastante lógico e racional, é necessário fazer uso de métodos que sinalizem, balizem e avaliem as propostas. Apesar desta área ser antiga no campo prático, ainda é bastante nova com relação a sua teorização. Trata-se de uma disciplina que vem crescendo e amadurecendo, mas carece ainda de uma maior discussão de seus conceitos e práticas (Scherer, 2014). Nesse sentido, modelos de metodologia voltados para as especificidades do design de sinalização vem sendo gerados para esquematizar e simplificar as fases do processo.

O design gráfico ambiental atua num campo multidisciplinar, exigindo que o profissional tenha habilidade em trabalhar a espacialidade, conheça as propriedades dos materiais e tenha domínio da composição visual. Em decorrência disso, muitos dos métodos empregados em projetos de sinalização mesclam processos encontrados em outras áreas, tais como, arquitetura, design gráfico e design de produto. Ainda que a metodologia aplicada em projeto de sinalização não seja tão difundida, pode-se notar que com o passar dos anos, os processos foram se aprimorando em esquemas prescritivos e mais maleáveis, adaptados aos problemas atuais.

O Núcleo de Design Gráfico Ambiental (NDGA) da Universidade Federal do Rio Grande do Sul (UFRGS), em 2012, realizou um levantamento de métodos, com a finalidade de propor uma metodologia que fosse ao mesmo tempo abrangente e específica. Abrangente ao trabalhar a complexidade em diferentes contextos - o espaço/ambiente, a informação e o usuário, bem como abarcar projetos de grande porte, como o caso das universidades, e suas implicações burocráticas. Específico ao tratar de aspectos particulares, tais como: manual, simulações virtuais e protótipos. 


\section{CIDI $2017{ }^{8 \mathrm{n}}$ CIII NATAL

O método proposto pelo NDGA é dividido em três grandes grupos: (1) planejamento, (2) projeto e (3) implementação, e que por sua vez são divididos em fases e estas subdivididas em etapas (Fig. 1).

Figura 1: Metodologia para desenvolvimento de sistemas de sinalização proposta pelo NDGA. Fonte: Cardoso, E. et al. [201-]

\section{PLANEJAMENTO}

\begin{tabular}{l} 
Contato \\
Estimativa de custo \\
Cronograma \\
Contrato \\
Escopo do projeto \\
Detalhamento \\
\hline
\end{tabular}

\section{PROJETO}

\begin{tabular}{|c|c|c|}
\hline Pesquisa & $\begin{array}{l}\text { Desenvolvimento } \\
\text { da proposta }\end{array}$ & Detalhamento \\
\hline $\begin{array}{l}\text { Espaço/ambiente } \\
\text { Usuário } \\
\text { Conteúdo/informação } \\
\text { Diretrizes do projeto } \\
\text { Análise de similares } \\
\text { Conceito }\end{array}$ & $\begin{array}{l}\text { - Apresentação e aprovação } \\
\text { - Geração de alternativas } \\
\text { - Seleção da alternativa } \\
\text { Avaliação } \\
\text { - Fechamento do sistema } \\
\text { Validação da proposta } \\
\text { Apresentação e aprovação }\end{array}$ & $\begin{array}{l}\text { Especificações } \\
\text { Manual do sistema }\end{array}$ \\
\hline \multicolumn{3}{|c|}{ IMPLEMENTAÇÃO } \\
\hline Orçamento & Produção & Instalação \\
\hline $\begin{array}{l}\text { Seleção de fornecedores } \\
\text { Protótipo de teste } \\
\text { Orçamento detalhado } \\
\text { Revisão do orçamento } \\
\text { e contratação }\end{array}$ & $\begin{array}{l}\text { Fabricação do sistema } \\
\text { Acompanhamento }\end{array}$ & $\begin{array}{l}\text { Inspeção } \\
\text { Avaliação com o cliente } \\
\text { Relatório final }\end{array}$ \\
\hline
\end{tabular}

O modelo, acima descrito, serviu de exemplo para o estudo proposto: um projeto de sinalização para o campus central da Universidade Federal do Rio Grande do Norte (UFRN). Desta maneira, esta pesquisa tem como objetivo analisar métodos que auxiliem à coleta de dados na fase de planejamento, composta pelo briefing, definição do escopo e cronograma do projeto.

\section{Método aplicado ao campus central da UFRN}

Ao longo dos anos, as instalações que compõem o campus da UFRN se expandiram e, sem o planejamento adequado, cresceram de modo desordenado, criando uma grande variedade de 


\title{
CIDI $2017 \quad 8^{\text {th }} \mathrm{CIDI}$

espaços que não seguem uma lógica de organização e tornam-se confusos para qualquer um que tente circular nestes ambientes. Tanto a comunidade externa como a interna se deparam com um sistema de sinalização que não se enquadram às necessidades do espaço, apresentando-se desatualizado e danificado pela ação do tempo ou por vandalismo. Para que tenha uma boa navegação nesses espaços, será necessário fazer uma análise detalhada do ambiente, os fluxos dos usuários e pontos de decisão.

Para a composição da primeira etapa do projeto, referente ao planejamento das informações, foi levado em consideração não somente a metodologia proposta pelo NDGA, como também foi realizada uma revisão bibliográfica, com o intuito de mesclar diferentes ferramentas que atendam as particularidades deste projeto. Desta maneira, estudou-se autores do âmbito do design gráfico e do design de serviços, tais como: Gibson (1950), Follis \& Hammer (1979), D’Agostini (2017) e Stickdorn \& Schneider (2014).

\section{Planejamento}

A fase de planejamento (Fig. 2) foi subdividida em: contato e levantamento de dados. A etapa de contato consiste na formulação do briefing, escopo do projeto e definição do cronograma, para que seja possível um melhor entendimento da demanda. Segundo Phillips (2007), essa fase tem como objetivo reunir, preliminarmente, as informações básicas sobre o problema e os sub-problemas, que resultará em seguida no seu escopo. Por se tratar de um ambiente público, a demanda não está relacionada a um cliente real, mas diretamente ligada ao diagnóstico e identificação do problema geral. Deste modo, uma das maneiras de se obter informações para o desenvolvimento do briefing é por meio de visitas técnicas.

Figura 2: Subdivisões da fase de planejamento. Fonte: Acervo pessoal.

\begin{tabular}{|l|l|}
\hline \multicolumn{2}{|c|}{ PLANEJAMENTO } \\
\hline Contato & Levantamento de Dados \\
\hline Briefing & Informações do espaço/ambiente \\
\hline Escopo do Projeto & Informações do usuário \\
\hline Cronograma & \\
\hline
\end{tabular}

O quadro a seguir (Fig. 3) mostra como o briefing se decompõe em etapas que detalham a situação inicial de um sistema que receberá a intervenção de design, de acordo com Corrêa et al. (2014). Os autores ainda afirmam que este processo é importante para minimizar as possibilidades de erros de projeto que, ao serem percebidos precocemente, permitem a prevenção ou correção com o menor impacto possível.

Figura 3: Quadro de divisão do briefing em etapas. Fonte: Adaptado de Corrêa et al., 2014.

\section{BRIEFING: IDENTIFICAÇÃO E ANÁLISE DO PROBLEMA}

\author{
- Missão ou meta \\ - Avaliação de necessidades \\ - Justificativa \\ - Definição do problema geral \\ - Divisão em subproblemas \\ - Delimitação do sistema-alvo \\ - Definição do público-alvo \\ - Estabelecimento de um programa \\ de trabalho
}




\section{CIDI $2017{ }^{8 n} \mathrm{CIDI}$ NataL

É importante observar que a última etapa do briefing nada mais é do que a definição do escopo do projeto, pois este faz uso das informações preliminares que estão disponíveis para montar um plano de trabalho. O escopo deve estabelecer: (1) o tipo de ambiente: se é aberto ou fechado; (2) a abrangência do projeto: se será implantado em uma unidade ou replicado para todos os locais; e (3) a abordagem do projeto: se trata de um sistema ou uma única aplicação. Segundo D'Agostini (2017), o sentido para a definição de um escopo de projeto está na delimitação das ações em um trabalho a partir de uma compreensão ampla sobre o ambiente, com o objetivo principal de atuar com a abordagem adequada e atender exclusivamente a demanda de comunicação do espaço em questão. Por fim, um cronograma é estabelecido como forma de organizar o tempo, aproveitando ao máximo todas as ações necessárias para a construção de um trabalho de sinalização.

A etapa de levantamento de dados divide-se, por sua vez, em dois campos igualmente importantes: os dados sobre o espaço/ambiente que necessita sinalizar e as informações sobre os usuários que circulam no local. Os dados sobre o espaço são aferidos por meio de planta baixa, corte e vista, associados aos levantamentos métricos e fotográficos do local, essenciais para um registro do estado atual do ambiente, que não somente proporcionam um panorama sobre os problemas de comunicação do local, como também expõe características importantes do determinado espaço.

Durante a visita ao local é indispensável as observações a respeito dos fluxos e pontos de decisão, conforme orienta D’Agostini (2017). Estas informações podem ser posteriormente traduzidas em fluxogramas e infográficos que ajudarão a determinar os pontos que deverão ser sinalizados e que tipo de sinalização será mais adequado nesses locais. Neste momento é importante também inferir sobre (1) a natureza do local: o ambiente é coberto ou descoberto; (2) a temporalidade: o ambiente é permanente ou temporário; (3) o tipo de fluxo: é um local de percurso, circulação ou espera; e, (4) a composição: o ambiente é composto por andares, blocos e/ou setores.

Para melhor visualizar e compreender a organização do ambiente é interessante desenvolver um sistema básico que identifique os principais acessos do lugar até chegar ao local exato que se está procurando (Fig. 4). Todo ambiente deve ser percebido como um grande sistema que, etapa após etapa, vai sendo assimilado pelos usuários. Trata-se, segundo D’Agostini (2017), de um processo de zonificação do ambiente, que determina setores, subsetores e demais locais que fazem parte de um mesmo espaço.

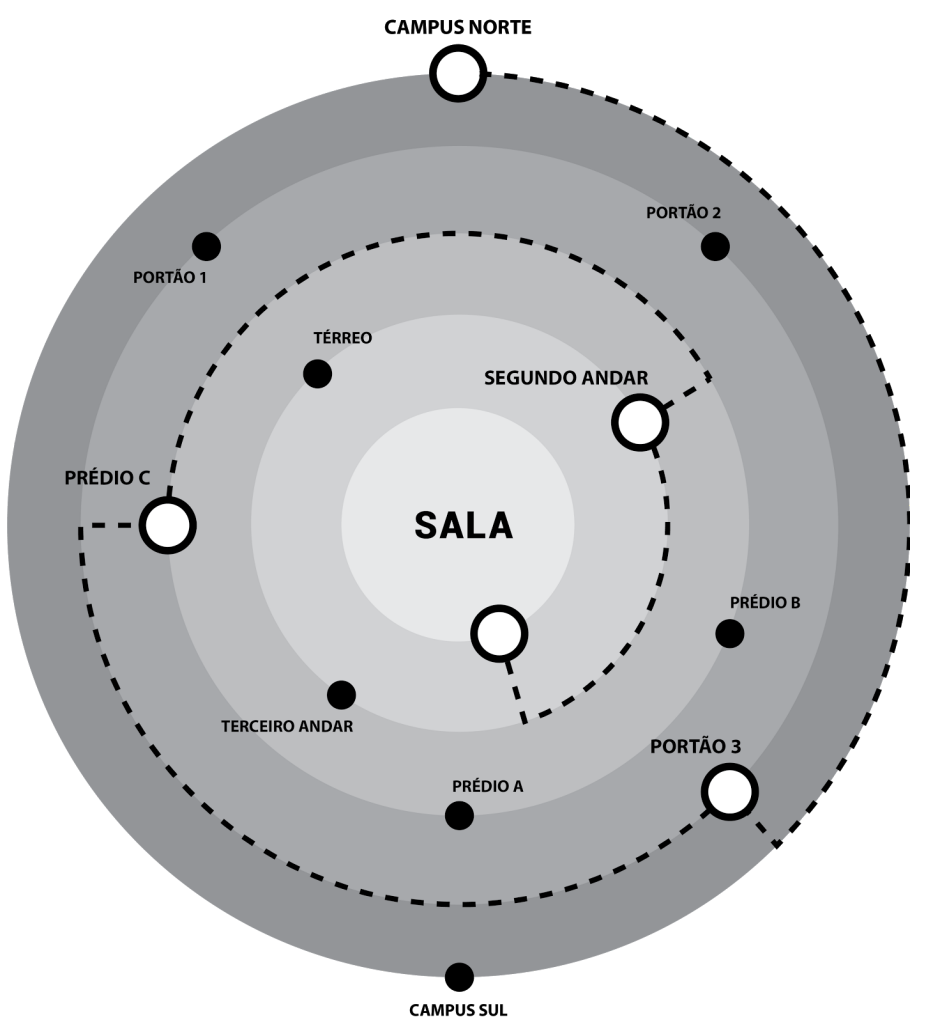


Se as informações do espaço são importantes, a coleta de dados com o usuário é essencial, principalmente se tratando de um ambiente edificado. Ao contrário de projetos de sinalização para ambientes não construídos, em que o designer é contratado ainda na fase de planejamento da obra, áreas que já estão em funcionamento possuem uma dinâmica de ocupação consolidada e que precisa ser respeitada (Chamma \& Pastorelo, 2007). O primeiro passo para que possamos compreender quais informações são relevantes é conhecer os dois grupos de usuários: o primeiro, possui familiaridade com o local; o segundo, é aquele que está entrando em contato com o ambiente pela primeira vez (D'Agostini, 2017).

Outros pontos que podemos destacar na coleta de informações sobre os usuários dizem respeito a forma como as pessoas irão captar a informação e como processam esses dados, além das circunstâncias em que o usuário se encontra. Por isso é essencial conhecer os limites sensoriais, cognitivos e físicos do público. Questões como a idade, a nacionalidade e a condição cultural dos usuários também repercutem em uma análise sobre o modo pelo qual eles irão processar e responder as mensagens colocadas no ambiente, tendo em vista suas experiências, aprendizados e formas de compreensão daquilo que é apresentado a eles (D’Agostini, 2017).

Todos esses conhecimentos podem ser adquiridos por meio da observação do usuário no ambiente, seguido de uma entrevista. Segundo Gil (1999) a observação "constitui elemento fundamental para a pesquisa", pois é a partir dela que é possível delinear as etapas de um estudo: formular problema, construir a hipótese, definir variáveis e coletar dados. Rudio (2002) reforça que o termo "observação" possui um sentido mais amplo, pois não se trata apenas de ver, mas também de examinar e é um dos meios mais frequentes para conhecer pessoas, coisas, acontecimentos e fenômenos. Conforme Sommer \& Sommer (2002), uma das vantagens do método de observação é que, se realizado de forma discreta e no mundo real, os comportamentos observados dos usuários serão mais espontâneos e naturais do que se forem realizados em laboratórios ou ambientes controlados.

Para este projeto optou-se por duas ferramentas de observação: (1) Fly on the wall, para aqueles que estão entrando em contato com o ambiente pela primeira vez; e (2) Shadowing, para aqueles que já estão familiarizados com o espaço. Ambos métodos são utilizados principalmente em design de serviços, no entanto, percebeu-se a aplicabilidade destes procedimentos para auxiliar no planejamento do design de sinalização.

Posterior às observações, serão realizadas uma série de perguntas por meio de entrevistas contextuais, em que o entrevistador se dirige ao usuário no ambiente da problematização, para gerar os insights desejados. Ademais, haverá coleta de dados pessoais (idade, nacionalidade e grau de escolaridade), juntamente com a solicitação de uma descrição da experiência do usuário dentro do campus e suas dificuldades, com o intuito de validar as respostas dadas na entrevista e confirmar o diagnóstico aferido durante o levantamento métrico e fotográfico. No entanto, os dados levantados com o usuário devem ser ponderados de acordo com a coerência as perguntas, podendo ser descartados durante a fase de sistematização das informações. Desta maneira, serão eliminados respostas que não apresentem coerência com os objetivos do projeto.

Por fim, com base nos dados sistematizados, será desenvolvido personas para a representação de cada grupo de usuários baseado em seus interesses em comum, além da criação de cenários que simulam as principais situações de orientação no ambiente. É importante salientar que algumas das informações adquiridas possam mudar aspectos do briefing e escopo do projeto, fazendo-se necessário retornar a estas etapas para revisar e modificar premissas equivocadas.

\section{Considerações finais}

Diante da complexidade do campus central da UFRN, o estudo procurou mostrar e discutir métodos que melhor se adequam às especificidades de um sistema de sinalização voltado a este tipo de ambiente público. No entanto, esta pesquisa encontra-se ainda em 
